\title{
Do we need a map to get through the maze?
}

\author{
Richard B. Schuessler, PhD
}

See related article on page 770 .

From the Washington University School of Medicine, Department of Surgery, Division of Cardiothoracic Surgery, St Louis, Mo.

Supported by research grant R01-HL32257 from the National Institutes of Health.

Received for publication Nov 3, 2003; revisions requested Nov 10, 2003; accepted for publication Nov 11, 2003.

Address for reprints: Richard B. Schuessler, PhD, Cardiothoracic Surgery Research, Box 8234, 3308 CSRB, 660 S Euclid, St Louis, MO 63110 (E-mail: schuesslerr@msnotes.wustl.edu).

J Thorac Cardiovasc Surg 2004;127:627-8

$0022-5223 / \$ 30.00$

Copyright ( $\odot 2004$ by The American Association for Thoracic Surgery

doi:10.1016/j.jtcvs.2003.11.004

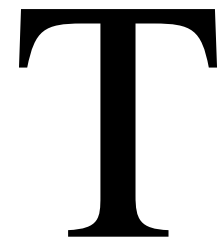

he procedure for the surgical ablation of accessory pathways in Wolff-Parkinson-White (WPW) syndrome, originally developed and performed by Will Sealy and John Boineau, established the paradigm for cardiac arrhythmia surgery. ${ }^{1,2}$ In that procedure, identification of the pathway was accomplished by intraoperative mapping. ${ }^{3}$

Originally, this required sequential recordings preformed with a single handheld electrode. Cox and associates ${ }^{4}$ further refined the technique by using a computerized multichannel mapping system that permitted the recording of electrograms from multiple sites simultaneously. Not only did these studies facilitate the treatment of the WPW syndrome, but they also provided insight into the basic electrophysiologic mechanisms underlying the arrhythmia. The combined insight into mechanism and the practical experience gained from intraoperative mapping allowed cardiologists to develop ablation and catheter techniques to perform the procedure less invasively. The net result is that the curative treatment of WPW is now routinely performed with a high efficacy and very low morbidity and mortality. Other cardiac arrhythmias, including focal atrial tachycardia, atrioventricular nodal reentrant tachycardia, atrial flutter, and ventricular tachycardia, followed the same paradigm.,

When we developed a procedure to surgically treat atrial fibrillation (AF), it was preceded by extensive mapping studies in both animals and humans. ${ }^{7,8}$ The intention was to follow the traditional paradigm and develop a procedure based on intraoperative mapping in which, as with WPW, a critical anatomic substrate essential for the fibrillation would be identified and surgically modified. However, the mapping data did not identify a stable identifiable substrate. With the limitation of the mapping technology and our limited understanding of the mechanisms of AF, we were unable to develop a map-directed procedure. However, the data from the animal and human studies suggested that certain anatomic structures facilitated fibrillation. In particular, naturally occurring obstacles such as the mitral and tricuspid anuli, the pulmonary veins, and the superior and inferior vena cava all were potential sites of macroreentry. In addition, the data and studies of other investigators established that large contiguous areas of tissue provided a substrate for potential reentrant circuits. This led to the development of an anatomic-based approach that culminated in the maze III procedure, which has become the gold standard for the nonpharmacologic treatment of AF. ${ }^{9}$

Since the development of the maze procedure, other anatomic-based procedures have been developed. One of these, the radial procedure, was developed in our laboratory by Nitta and associates ${ }^{10,11}$ to optimize left atrial function while still maintaining the high cure rate of the maze III procedure. In this issue, Nitta revisits the original paradigm, in which he uses intraoperative mapping to identify the critical anatomic substrate underlying an individual patient's AFs. ${ }^{12}$ This study is based on developments in our understanding of AF that have occurred since the introduction of the original maze and radial procedures. At that time, it was widely accepted that $\mathrm{AF}$ was maintained by multiple reentrant circuits, which were continuously and randomly changing their anatomic location. This was known as the multiple wavelet hypothesis. In 1991, we performed studies in isolated atrial tissue in which we demonstrated that AF could be maintained by a single stable circuit with fibrillatory conduction away from that circuit. ${ }^{13}$ Others observed this type of fibrillation in intact animal studies. ${ }^{14,15}$ Haissaguerre and associates ${ }^{16}$ demonstrated that some patients had AF originating from a single site within the pulmonary veins 
and that ablation of limited amounts of tissue could stop the fibrillation. Yamauchi and colleagues ${ }^{17}$ and Harada and associates ${ }^{18}$ have also demonstrated that in patients with mitral disease, focal sources of AF have been observed. These data all suggest that AF may be treatable by a more limited map-directed procedure. In the study reported in this issue, Nitta and colleagues ${ }^{12}$ mapped the atrial epicardium in patients with persistent $\mathrm{AF}$ and mitral valve disease to test this concept. They identify a novel form of AF. They showed that the fibrillation in their patients was being maintained by 2 simultaneous sources and that these were stable over the recording period. This study is important for 2 reasons. First, it demonstrates that the sources of fibrillation can be identified during operation. Second, it adds new information to our understanding of AF. As pointed out by the authors, several questions need to be answered before intraoperative mapping can be used to modify the maze or radial procedures. First, the long-term stability of the sources needs to be demonstrated. Second, will ablation of individual sources unmask other sources? Third, mapping techniques need to be improved to facilitate the localization of the sources. Presently, activation sequence mapping can be time consuming. Fourth, a beating-heart approach to the maze or radial procedure needs to be developed. This would allow the surgeon to ablate the critical tissue and observe the termination of the arrhythmia while limiting pump and crossclamp time. Under the leadership of Ralph Damiano, we are working to develop newer mapping techniques to facilitate intraoperative mapping and have already demonstrated in an animal model that the maze procedure can be performed in a beating heart. ${ }^{19}$ Finally, any approach to treatment of fibrillation must show the long-term efficacy of the maze procedure.

So do we need a map to get through the maze? The present study of Nitta and associates does not conclusively demonstrate that it is needed at this time. However, the study does increase our understanding of $\mathrm{AF}$, and it does demonstrate that the sources can be identified. Much work needs to be done, and I anticipate that Nitta and his coworkers will be at the forefront of this research. This could lead us to re-establish the original paradigm of arrhythmia surgery as formulated by Sealy and Boineau 30 years ago. ${ }^{1,2}$ What is the benefit? If AF can be cured by a directed and more limited ablation, a less extensive procedure can be performed and less invasive approaches can be used. Ultimately, it is the patients who will benefit. A more limited curative procedure will be less risky. This could increase the number of patients who could benefit from such a procedure. It is hoped that, in the future, ablation of AF will be as common and safe as ablation of WPW is today. Nitta and coworkers are leading us in that direction.

\section{References}

1. Sealy WC, Boineau JP, Wallace AG. The identification and division of the bundle of Kent for premature ventricular excitation and supraventricular tachycardia. Surgery. 1970;68:1009-17.

2. Cobb FR, Blumenschein SD, Sealy WC, Boineau JP, Wagner GS, Wallace AG. Successful surgical interruption of the bundle of Kent in a patient with Wolff-Parkinson-White syndrome. Circulation. 1968; 38:1018-29.

3. Boineau JP, Moore EN, Sealy WC, Kasell JH. Epicardial mapping in Wolff-Parkinson-White syndrome. Arch Intern Med. 1975;135:42231.

4. Cox JL, Gallagher JJ, Cain ME. Experience with 118 consecutive patients undergoing surgery for the Wolff-Parkinson-White syndrome. J Thorac Cardiovasc Surg. 1985;90:490-501.

5. Cox L. The surgical management of cardiac arrhythmias. In: Sabiston DC, Spencer FC, editors. Surgery of the chest. 6th ed. Philadelphia: WB Saunders; 1995. p. 2033-68.

6. Wittig JH, Boineau JP. Surgical treatment of ventricular arrhythmias using epicardial, transmural, and endocardial mapping. Ann Thorac Surg. 1975;20:117-26.

7. Cox JL, Schuessler RB, Boineau JP. The development of the Maze procedure for the treatment of atrial fibrillation. Semin Thorac Cardiovasc Surg. 2000;12:2-14.

8. Cox JL, Canavan TE, Schuessler RB, Cain ME, Lindsay BD, Stone C, et al. The surgical treatment of atrial fibrillation: II. Intraoperative electrophysiologic mapping and description of the electrophysiologic basis of atrial flutter and atrial fibrillation. J Thorac Cardiovasc Surg. 1991;101:406-26.

9. Prasad SM, Maniar HS, Camillo C, Schuessler RB, Sundt T, Cox JL, et al. The Cox maze III operation for atrial fibrillation: long-term efficacy in patients undergoing lone versus concomitant procedures. J Thorac Cardiovasc Surg. 2003;126:1822-8.

10. Nitta T, Lee R, Schuessler RB, Boineau JP, Cox JL. Radial approach: a new concept in surgical treatment for AF. I. Concept, anatomic and physiologic bases and development of a procedure. Ann Thorac Surg. 1999;67:27-35.

11. Nitta T, Lee R, Watanabe H, Harris KM, Erikson JM, Schuessler RB, et al. Radial approach: a new concept in surgical treatment for AF. II. Electrophysiologic effects and atrial contribution to ventricular filling. Ann Thorac Surg. 1999;67:36-50.

12. Nitta T, Ishii Y, Miyagi Y, Ohmori H. Sakamoto S, Tanaka S. Concurrent multiple left atrial focal activations with fibrillatory conduction and right atrial focal or reentrant activation as the mechanism in atrial fibrillation. J Thorac Cardiovasc Surg. 2004;127:770-8.

13. Schuessler RB, Grayson TM, Bromberg BI, Cox JL, Boineau JP. Cholinergically mediated tachyarrhythmias induced by a single extrastimulus in the isolated canine right atrium. Circ Res. 1992;71:125467.

14. Yamauchi S, Boineau JP, Schuessler RB, Cox JL. Varying types of circus movement re-entry with both normal and dissociated contralateral conduction causing different right and left atrial rhythms in canine atrial flutter. Jpn Circ J. 1998;62:201-10.

15. Mandapati R, Skanes A, Chen J, Berenfeld O, Jalife J. Stable microreentrant sources as a mechanism of atrial fibrillation in the isolated sheep heart. Circulation. 2000;101:194-9.

16. Haissaguerre M, Jais P, Shah DC, Takahashi A, Hocini M, Quiniou G, et al. Spontaneous initiation of atrial fibrillation by ectopic beats originating in the pulmonary veins. N Engl J Med. 1998;339:659-66.

17. Yamauchi S, Tanaka S, Asano T, Harada A, Nitta T, Hioki M, et al. Efficacy of combining mapping with surgery of atrial fibrillation. Rinsho Kyobu Geka. 1994;14:344-5.

18. Harada A, Sasaki K, Fukushima T, Ikeshita M, Asano T, Yamauchi S, et al. Atrial activation during chronic atrial fibrillation in patients with isolated mitral valve disease. Ann Thorac Surg. 1996;61:104-11.

19. Gaynor SL, Ishii Y, Diodato M, Prasad SM, Barnett KM, Damiano NR, et al. Successful performance of the Cox-maze procedure on the beating heart without cardiopulmonary bypass: a chronic animal study using bipolar radiofrequency ablation. Pace. 2003;26:1068. 